\title{
Translation and Validation of Fear of Pain-9 Items into Simplified Chinese Version for Mainland China
}

\author{
Yang Luo $\mathbb{1 D}^{1, *}$ \\ Sisi $\mathrm{Li}^{2}$,* \\ Jingting $\mathrm{He}^{1}$ \\ Dan $\mathrm{Cai}^{3}$ \\ Yi Dai ${ }^{3}$ \\ Lijuan Feng' \\ Chengqin Sun' \\ Xiaoping $\mathrm{Zhu}^{4}$ \\ 'Department of Thoracic Surgery, Union \\ Hospital, Tongji Medical College, \\ Huazhong University of Science and \\ Technology, Wuhan, People's Republic of \\ China; ${ }^{2}$ Department of Colorectal and \\ Anal Surgery, Zhongnan Hospital of \\ Wuhan University, Wuhan, People's \\ Republic of China; ${ }^{3}$ Nursing Department, \\ Union Hospital, Tongji Medical College, \\ Huazhong University of Science and \\ Technology, Wuhan, People's Republic of \\ China; ${ }^{4}$ Nursing Department, Zhongnan \\ Hospital of Wuhan University, Wuhan, \\ People's Republic of China
}

*These authors contributed equally to this work

Correspondence: Jingting $\mathrm{He}$ Department of Thoracic Surgery, Union Hospital, Tongji Medical College, Huazhong University of Science and Technology, 1277 JieFang Avenue, Wuhan 430022, People's Republic of China Tel +86 I5007I 22833

Fax +862785871829

Email hejingting@hust.edu.cn
This article was published in the following Dove Press journal: Journal of Pain Research

Purpose: This study aimed to obtain a translation and validation of the Fear of Pain Questionnaire 9 Items (FOP-9) into simplified Chinese.

Methods: The questionnaire was translated following the forward-backward method. The final version was filled out by $(\mathrm{n}=300)$ patients. Cronbach's coefficient was calculated to test the internal consistency of simplified Chinese version of FOP-9 (sc-FOP-9), and 50 painless patients completed the sc-FOP-9 questionnaire within a 2-weeks interval to evaluate test-retest reliability. To verify the construct validity, exploratory factor analysis was used to explore the factor structure, and confirmatory factor analysis was conducted to evaluate the goodness fit of models.

Results: Satisfactory psychometric qualities were obtained (Cronbach's $\alpha$ of the total score was 0.873 and intraclass correlation coefficient was 0.975 ). Three first-order models were tested and all show a good model fit and the 3-factor structure may be better due to its higher factor loading.

Conclusion: The sc-FOP-9 is a reliable and valid instrument to evaluate the fear of pain among Chinese patients with or without pain. Fear of pain may have an important effect on perioperative pain and chronic pain, and this tool is a good complement to the measurement in mainland China.

Keywords: fear of pain, reliability, validity, Chinese, pain-related fear

\section{Introduction}

Pain is something we all experience as we grow up. Virtually, everyone can recall in minutes the details of a painful event, even if it happened decades ago. Brains are wired for this, with a strong emotional component, which makes some pain literally "hard to forget." Powerful memories of pains often lead to maladaptive fear of pain (FOP)/pain-related fear that heightens and perpetuates the pain cycle and keeps people away from activities and from other people. ${ }^{1}$

A lot of studies in the past decades have illustrated the significance of psychological and social factors in the development of chronic pain as well as acute pain, and discovered that FOP may strongly impact pain perception and avoidance behaviors. ${ }^{2}$ With higher FOP when experiencing painful events, nonclinical patients may report higher pain degrees, ${ }^{3}$ whereas chronic patients may report more pain density, worse activity performance and lower quality of life. ${ }^{4,5}$

To assess FOP in the pain population, professor McNeil developed the fear of pain questionnaire-III (FOP-III) ${ }^{6}$ in 1998 , which has been widely validated in many 
different countries, including China, ${ }^{7}$ Portugal, ${ }^{8}$ Turkey, ${ }^{9}$ Dutch, ${ }^{10}$ Italy, ${ }^{11}$ and Brazil, ${ }^{12}$ and exhibited excellent reliability and validity in various cultures. Although it has been confirmed applicable to evaluating not only trait FOP but also state FOP in nonclinical ${ }^{13}$ and clinical people, ${ }^{14}$ FOP-III is still not brief enough for the administration of patients in busy outpatient and inpatient settings. To improve clinical practicability and efficiency, professor McNeil developed the fear of pain questionnaire 9 items (FOP-9) ${ }^{15}$ - a shorter form of FOP-III- in 2017. The FOP-9 has been proved to have acceptable reliability and validity and seems to be a promising brief FOP measure instrument.

Unfortunately, the simplified Chinese version of fear of pain questionnaire 9 items (sc-FOP-9) is not available in mainland China. Therefore, this study aims to translate the FOP-9 into the simplified Chinese version and validate the psychometric properties of the sc-FOP-9.

\section{Methods}

\section{Study Design}

This study was approved by the institutional ethics board of Wuhan Union Hospital of Tongji Medical College, Huazhong University of Science and Technology. The eligibility criteria included (a) age 18 years and above (according to the age criteria of Chinese adults), (b) Chinese-speaking, (c) non-illiteracy, (d) able to give informed consent, and (e) no presence or history of a neurological or psychiatric disorder. All participants were asked to provide written and oral informed consent. The recommended sample size for confirmatory factor analysis is at least 300 cases. $^{16}$

\section{Participants}

From June to September 2020, 300 patients from Wuhan Union Hospital and Zhongnan Hospital of Wuhan University, two tertiary hospitals in Wuhan, were enrolled in the study, including 100 painless patients attending the thoracic and gastrointestinal surgery clinics, 100 patients with chronic pain (13 outpatients and 87 inpatients at the pain unit), and 100 patients with acute pain after surgery (54 underwent thoracoscopic and 46 underwent abdominal surgery). All participants were asked to provide sociodemographic (ie gender, age, education level) and clinical information (ie history or presence of psychiatric or neurological disorders and presence of pain). Fifty participants were asked to complete the sc-FOP-9 twice to test the retest reliability, and the time to finish the questionnaire was recorded for the first time. Each of the participants was asked to rate the instructions and items of the pre-final simplified Chinese version using a dichotomous scale (clear or unclear). (Participant recruiting details could be seen in Figure 1)

\section{Translation and Cross-Cultural Adaptation}

The translation and cross-cultural adaptation of FOP-9 into a simplified Chinese version were conducted by following the guidelines. ${ }^{17}$ Two Mandarin-speaking bilingual translators, one is a university English teacher and the other is a doctor who has lived in an English-speaking country for more than three years, forward translated two original versions into simplified Chinese independently. A third bilingual independent translator compared the two forwardtranslated simplified Chinese versions regarding the ambiguities and discrepancies of words, sentences, and meanings. Some ambiguities and discrepancies were discussed and resolved by a committee consisting of three translators, a clinician, and a nurse who generated the preliminary scFOP-9. Subsequently, two English-speaking translators majoring in Chinese specialism completed the backward translation, respectively. The differences between the two backward-translation versions and the original FOP-9 were resolved by the committee, and the pre-final simplified Chinese version was formed. The pilot testing of the prefinal version was performed, in which two items were adjusted. Then, the final sc-FOP-9 was finished after thorough revision by an expert panel consisting of five

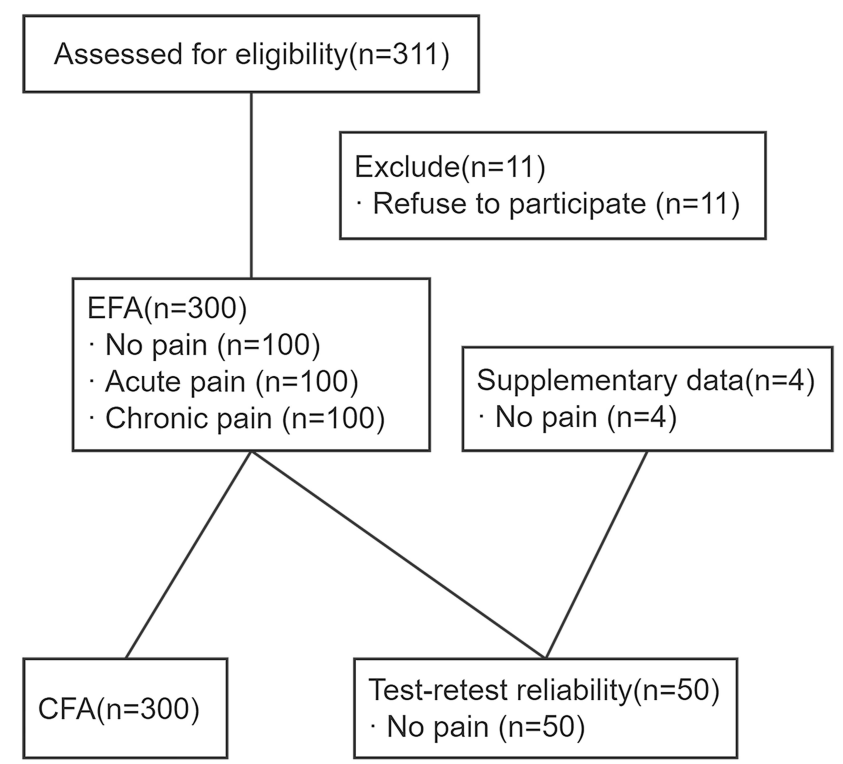

Figure I Flow chart of participants. EFA, exploratory factor analysis. CFA, confirmatory factor analysis. 
translators, two clinicians, two nurses, one psychologist, and one statistician.

\section{Validation}

\section{Internal Consistency}

To test the internal consistency, coefficient alpha was calculated for each of the subscales individually as well as for the total score. An alpha value ranging from 0.7 to 0.95 was considered adequate. ${ }^{18}$ The corrected item-total correlation coefficient was calculated for each item, and the value was expected to exceed $0.4 .^{19}$

\section{Test-Retest Reliability}

The test-retest reliability was assessed using an intraclass correlation coefficient that varies from 0 to 1 . If the result is above 0.8 , the test-retest reliability is considered excellent. $^{20}$

\section{Construct/Factorial Validity}

Factorial validity was applied to measure the correlation between a group of questionnaire items and a specific factor (construct). KMO and Bartlett's test of sphericity was used to determine whether the data is suitable for factor analysis. Exploratory factor analysis (EFA) with varimax rotation was used to explore the possible structure of the scale. Confirmatory factor analysis (CFA) was conducted to verify the construct validity by fit indices and commended values of indices should be followed by: (1) CMIN/DF < 3.00; (2) NFI > 0.90; (3) CFI > 0.90; (4) GFI $>$ 0.90 ; (5) RMSEA $<0.08$.

\section{Questionnaire}

The fear of pain questionnaire 9 items (FOP-9) was first presented in 2018. It is a shortened version of the Fear of Pain Questionnaire-III (FPQ-III) ${ }^{6}$ and a 9 items self-report questionnaire designed to measure the fear of pain. It is composed of three subscales: fear of severe pain, fear of minor pain, and fear of medical pain. Each subscale contains 3 items rated on a 5-point Likert scale (1 to 5). The total score was calculated by adding the scores of all 9 items, and high scores indicate high FOP. The authors reported that good psychometric properties of FOP-9 have been manifested reasonable reliability (Cronbach's alpha values from 0.72 to 0.94 ) and validity (confirmatory factor analysis model fit: RMSEA $=0.00, \mathrm{CFI}=1.00, \mathrm{TLI}$ $=1.00, \mathrm{SRMR}=0.03$ ) in chronic patients and nonclinical people. The authors declared in the original paper that permission was given for users to reproduce the instrument for clinical and research purposes.

\section{Statistical Analysis}

Analyses were performed in SPSS version 22.0 and AMOS version 20.0 for Windows (Chicago, IL, USA). A p-value of less than 0.05 was considered statistically significant for all analyses. Descriptive data were presented as the mean \pm standard deviation (SD) and percentages. The percentage of missing data was considered acceptable if the value was less than 5\%. Floor and/or ceiling effects were considered present if the proportion of the lowest and/or highest scores on the scale exceeded $15 \% .^{18}$

\section{Results}

A total of 300 patients were interviewed. Table 1 presents the demographics and clinical characteristics of participants. The descriptive statistics of the sc-FOP-9 subscale and summary scores are detailed in Table 2. Among the participants, $98.0 \%(49 / 50)$ agreed that the translated questionnaire was clearer and more understandable, and 2.0\% disagreed. The average time to complete the questionnaire was 86.3 seconds.

Cronbach's $\alpha$ of subscales was from 0.737 to 0.823 and of the total score was 0.873 . The corrected item-total correlation coefficient was all above 0.5 , indicating that the sc-FOP-9 had good internal consistency. The intraclass correlation coefficient 0.975 showed that the sc-FOP-9 had excellent test-retest reliability (Table 3 ).

Table I Demographic and Clinical Characteristics $(n=300)$

\begin{tabular}{|l|l|}
\hline $\begin{array}{l}\text { Gender, \% (n) } \\
\text { Male }\end{array}$ & $174(58.0)$ \\
Female & $126(42.0)$ \\
\hline Age, mean \pm SD & $53.9 \pm 13.2$ \\
\hline Pain, \% (n) & \\
No pain & $100(33.3)$ \\
Acute (<4 weeks) & $100(33.3)$ \\
Chronic ( $\geq 4$ weeks) & $100(33.3)$ \\
\hline Education, \% (n) & $37(12.3)$ \\
Primary school & $92(30.7)$ \\
Middle school & $60(20.0)$ \\
High school & $111(37.0)$ \\
University &
\end{tabular}

Abbreviation: SD, standard deviation. 
Table 2 Descriptive Statistics and Internal Consistency of sc-FOP-9 $(n=300)$

\begin{tabular}{|c|c|c|c|c|c|c|}
\hline Item & Original Version & Mean \pm SD & $\begin{array}{l}\text { Corrected Item- } \\
\text { Total Correlation }\end{array}$ & $\begin{array}{l}\text { Cronbach's } \\
\text { Alpha }\end{array}$ & $\begin{array}{l}\text { Floor } \\
\text { Effect (\%) }\end{array}$ & $\begin{array}{l}\text { Ceiling } \\
\text { Effect (\%) }\end{array}$ \\
\hline \multicolumn{2}{|c|}{ Fear of severe pain } & $10.45 \pm 2.57$ & & 0.769 & & \\
\hline 1 & Breaking your arm & $3.44 \pm 1.03$ & 0.618 & & 3.3 & 12.3 \\
\hline 6 & $\begin{array}{l}\text { Having someone slam a heavy car door on your } \\
\text { hand }\end{array}$ & $3.49 \pm 1.03$ & 0.626 & & 3.0 & 13.7 \\
\hline 9 & Falling down a flight of concrete stairs & $3.52 \pm 1.04$ & 0.573 & & 3.7 & 13.3 \\
\hline \multicolumn{2}{|c|}{ Fear of medical pain } & $8.88 \pm 2.65$ & & 0.737 & & \\
\hline 2 & $\begin{array}{l}\text { Having a foot doctor remove a wart from your } \\
\text { foot with a sharp instrument }\end{array}$ & $3.21 \pm 1.12$ & 0.638 & & 8.0 & 9.0 \\
\hline 4 & Receiving an injection in your mouth & $3.14 \pm 1.10$ & 0.651 & & 7.7 & 10.0 \\
\hline 8 & Receiving an injection in your hip/buttocks & $2.53 \pm 1.05$ & 0.607 & & 14.3 & 5.0 \\
\hline \multicolumn{2}{|c|}{ Fear of minor pain } & $7.32 \pm 2.64$ & & 0.823 & & \\
\hline 3 & Getting a papercut on your finger & $2.38 \pm 1.03$ & 0.592 & & 13.7 & 3.3 \\
\hline 5 & $\begin{array}{l}\text { Getting strong soap in both your eyes while } \\
\text { bathing or showering }\end{array}$ & $2.39 \pm 1.02$ & 0.584 & & 14.3 & 4.3 \\
\hline 7 & $\begin{array}{l}\text { Gulping a hot drink before it has cooled } \\
\text { Total }\end{array}$ & $\begin{array}{l}2.76 \pm 1.22 \\
26.66 \pm 6.69\end{array}$ & 0.609 & 0.873 & 13.0 & 9.7 \\
\hline
\end{tabular}

Note: See Supplementary Table I for translation in Simplified Chinese for items listed in each fear of pain category. Abbreviation: SD, standard deviation.

Table 3 Model Fit Indices of sc-FOP-9 After Bollen-Stine Bootstrap Modification $(n=300)$

\begin{tabular}{|l|l|l|l|l|l|l|}
\hline Model & CMIN & CMIN/DF & NFI & CFI & GFI & RMSEA \\
\hline One-factor & 1124.920 & 1.15 & 0.97 & 1.00 & 0.97 & 0.02 \\
Two-factor & 1128.007 & 1.07 & 0.98 & 1.00 & 0.98 & 0.02 \\
Three-factor & 1129.773 & 1.09 & 0.98 & 1.00 & 0.98 & 0.02 \\
\hline
\end{tabular}

Abbreviations: CMIN, chi square; DF, degree of freedom; NFI, normed fit index; CFI, comparative fit index; GFI, goodness-of-fit index; RMSEA, standardized root mean square error of approximation.

Bartlett's test of sphericity returned a significant result: $\mathrm{x}^{2}(36)=1141.042, \mathrm{p}<0.001$ and $\mathrm{KMO}=0.885$, which suggested that the sc-FOP-9 had an adequate common variance for factor analysis.

EFA in varimax rotation extracted a 2-factor structure with eigenvalues greater than 1 that jointly accounted for $63.9 \%$ of the total variance. The first factor (item $1,2,4,6,9)$ of sc-FOP-9 accounts for $50.2 \%$ of the total variance, and the second factor (item 3,5,7,8) accounts for $13.7 \%$.

CFA was performed to evaluate the latent structure of the sc-FOP-9. More specifically, three first-order models were tested, including a one-factor model, a two-factor model (according to EFA), and a three-factor model (according to the original version) which were all fitted to the data. The data in this study was at the ordinal level; therefore, the SEM assumption of multivariate normality was not possible. Besides, the Mardia's coefficient for multivariate kurtosis was $4.959(>3)$, indicating significant multivariate nonnormality in the data. As a result, Bollen-Stine bootstrap procedure (2000 samples) was used to adjust model fit and parameter estimates to accommodate the lack of multivariate normality. The model fit indices are presented in Table 3 . The estimates of factor loading and correlations among exogenous variables are presented in Figure 2.

\section{Discussion}

Currently, the Chinese version of FOP-III ${ }^{7}$ is the only tool which can be used to measure the FOP in mainland China, but in our early researches, it is not appropriate for evaluating low education people due to the unclear translation. As outpatient and inpatient departments of tertiary hospitals in China are 


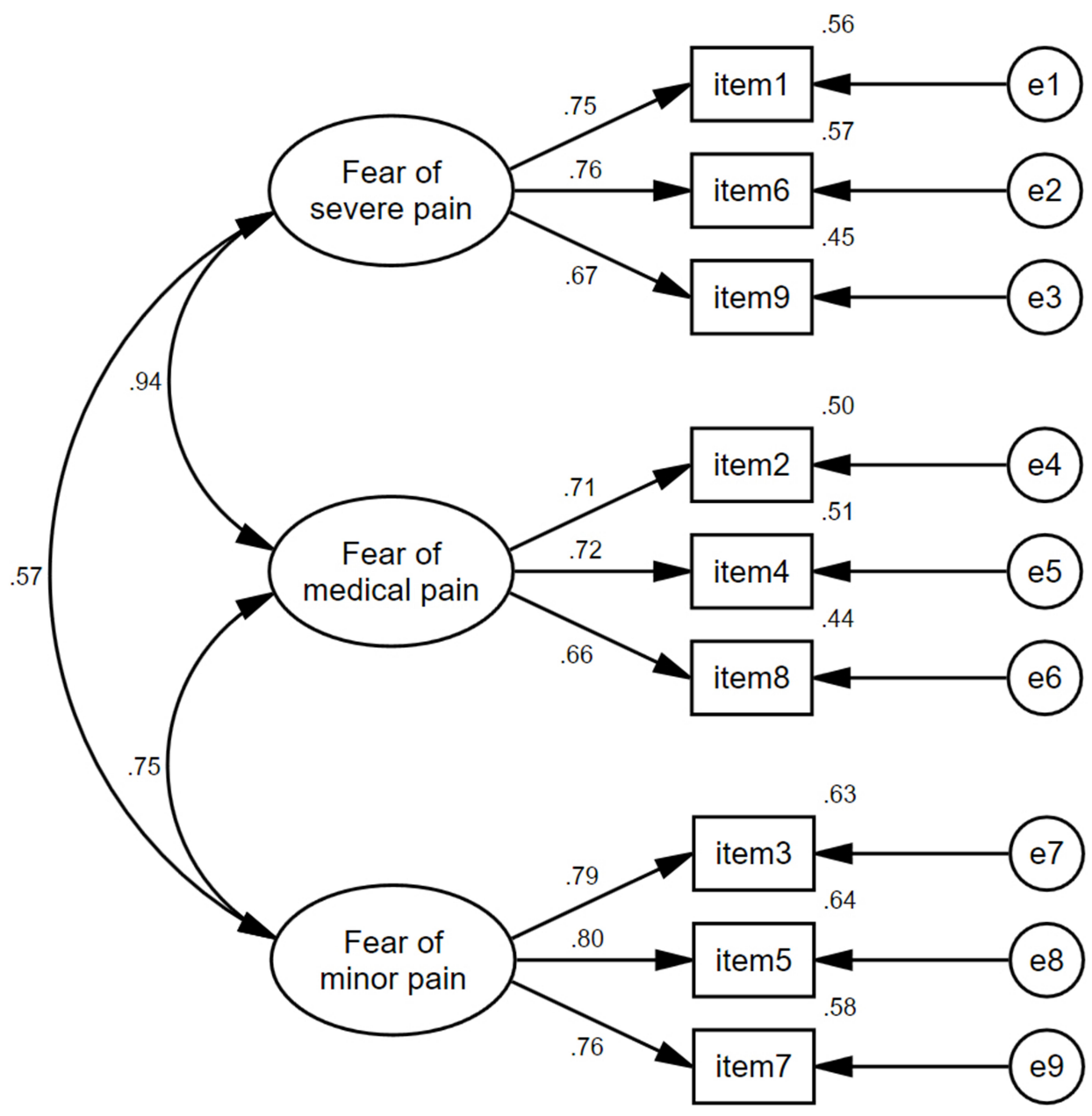

Figure 2 Three-factor structure of sc-FOP-9 with standardized parameter estimates $(n=300)$.

always busy, this study aims to create a shortened version of an instrument that measures FOP more efficiently in clinical settings, which is the same as the purpose of the authors of the original version. It took an average of fewer than two minutes to complete the questionnaire, which allowed clinicians to screen FOP levels of patients more quickly.

The result has shown that sc-FOP-9 has good reliability and validity. The internal consistency is above 0.80 (internal consistency); therefore, the sc-FOP-9 was considered to have excellent reliability. ${ }^{18,20}$ All the three first-order models showed a good model fit after Bollen-Stine bootstrap procedure, which indicates that the scale has good structural validity. Among them, factor analysis reveals a 2-factor solution which contains latent variable named "fear of severe/rare pain" and "fear of minor/common pain". In the 3-factor model, each item gets a better factor loading but multicollinearity exists between latent variables "Severe" and "Medical" (the correlation is 0.94 ). This may be caused by the little difference between the latent variables, fear of medical pain and fear of severe pain, in Chinese people.

Compared with the original authors, we studied not only painless and chronic people but also acute pain patients to ensure that the sc-FOP-9 is available to a wider population.

The limitation of this study is that all the studied samples are from two tertiary hospitals in Wuhan and most of them have higher education, which may not represent the heterogeneity of the whole population in mainland China. Therefore, future studies should focus more on economically underdeveloped areas.

\section{Conclusion}

This study proved that the sc-FOP-9 has sound reliability and validity, and suggested that the measures could be safely and quickly taken to evaluate the FOP in researches and clinical settings in people with or without pain. The 
researches related to FOP will still continue in China, and the findings of this study will be a good supplement and preliminary basis.

\section{Acknowledgments}

The authors would like to thank Professor Yang Dong of the Pain Department for his kind advice and help in this study.

\section{Disclosure}

The authors report no conflicts of interest in this work.

\section{References}

1. Nees F, Becker SJN. Psychological processes in chronic pain: influences of reward and fear learning as key mechanisms-behavioral evidence, neural circuits, and maladaptive changes. Neuroscience. 2018;387:72-84. doi:10.1016/j.neuroscience.2017.08.051

2. Gatchel RJ, Neblett R, Kishino N, Ray CT. Fear-avoidance beliefs and chronic pain. J Orthop Sports Phys Ther. 2016;46(2):38-43. doi:10.2519/jospt.2016.0601

3. Yang Z. Identifying pain perceptual biases related to fear of pain and threat in a pain-free sample. Eur J Pain. 2020;24(6):1084-1093. doi:10.1002/ejp. 1553

4. Markfelder T, Pauli P. Fear of pain and pain intensity: meta-analysis and systematic review. Psychol Bull. 2020;146(5):411-450. doi:10.1037/bul0000228

5. Mittinty MM, Brennan DS, Randall CL, McNeil DW, Mittinty MN, Jamieson L. Influence of fear of pain and coping strategies on health-related quality of life and patient-anticipated outcomes in patients with chronic pain: cross-sectional study protocol. JMIR Res Protoc. 2017;6(9):e176. doi:10.2196/resprot.8205

6. McNeil DW, Rainwater AJ 3rd. Development of the fear of pain questionnaire-III. J Behav Med. 1998;21(4):389-410. doi:10.1023/ a: 1018782831217

7. Yang Z, Meng J, Jackson T, Chen H. The reliability and validity of the fear of pain questionnaire-III. Chin J Clin Psychol. 2013;21(5):768770,773. doi:10.16128/j.cnki.1005-3611.2013.05.009

8. Cardoso S, Esculpi D, Carvalho AR, et al. Fear of Pain Questionnaire: adaptação para o português europeu. [The European Portuguese adaptation of the Fear of Pain Questionnaire]. Rev Bras Reumatol. 2016;56 (5):377-383. doi:10.1016/j.rbr.2015.10.006
9. Ünver S, Turan FN. Ağrı korkusu ölçeği-III'ün Türkçe geçerlilik ve güvenilirlik çalışması. [Turkish validity and reliability study of fear of pain questionnaire-III]. Agri $=J$ Turk Soc Algol. 2018;30 (1):18-27. doi:10.5505/agri.2017.62681

10. Dekker C, Bastiaenen CHG, de Vries JE, Simons LE, Goossens MEJB, Verbunt JAMCF. Dutch version of the fear of pain questionnaire for adolescents with chronic pain. Disabil Rehabil. 2017;40(11):1326-1332. doi:10.1080/ 09638288.2017 .1289255

11. Di Tella M, Ghiggia A, Testa S, Castelli L, Adenzato M. The fear of pain questionnaire: factor structure, validity and reliability of the Italian translation. PLoS One. 2019;14(1):e0210757. doi:10.1371/ journal.pone.0210757

12. Berniger Romariz JA, Nonnemacher C, Abreu M, et al. The fear of pain questionnaire: psychometric properties of a Brazilian version for adolescents and its relationship with brain-derived neurotrophic factor (BDNF). J Pain Res. 2019;12:2487-2502. doi:10.2147/jpr. S199120

13. Osman A, Breitenstein JL, Barrios FX, Gutierrez PM, Kopper BA. The fear of pain questionnaire-III: further reliability and validity with nonclinical samples. J Behav Med. 2002;25(2):155-173. doi:10.1023/ a: 1014884704974

14. Flack F, Gerlach AL, Simons LE, Zernikow B, Hechler T. Validation of the German fear of pain questionnaire in a sample of children with mixed chronic pain conditions. Eur J Pain. 2017;21(7):1224-1233. doi:10.1002/ejp.1022

15. McNeil DW, Kennedy SG, Randall CL, et al. Fear of pain questionnaire-9: brief assessment of pain-related fear and anxiety. Eur J Pain. 2018;22(1):39-48. doi:10.1002/ejp.1074

16. Tabachnick BG, Fidell LS. Using Multivariate Statistics (6th Edition). Harper and Row; 2012:1024.

17. Sousa VD, Rojjanasrirat W. Translation, adaptation and validation of instruments or scales for use in cross-cultural health care research: a clear and user-friendly guideline. J Eval Clin Pract. 2011;17 (2):268-274. doi:10.1111/j.1365-2753.2010.01434.x

18. Terwee CB, Bot SD, de Boer MR, et al. Quality criteria were proposed for measurement properties of health status questionnaires. J Clin Epidemiol. 2007;60(1):34-42. doi:10.1016/j. jclinepi.2006.03.012

19. Smith GT, McCarthy DM, Anderson KG. On the sins of short-form development. Psychol Assess. 2000;12(1):102-111. doi:10.1037/ 1040-3590.12.1.102

20. Plichta SB, Kelvin EA. Munro's Statistical Methods for Health Care Research: Sixth Edition; Lippincott williams \& wilkins; 2011:1-567.
Journal of Pain Research

\section{Publish your work in this journal}

The Journal of Pain Research is an international, peer reviewed, open access, online journal that welcomes laboratory and clinical findings in the fields of pain research and the prevention and management of pain. Original research, reviews, symposium reports, hypothesis formation and commentaries are all considered for publication. The manuscript management system is completely online and includes a very quick and fair peer-review system, which is all easy to use. Visit http:// www.dovepress.com/testimonials.php to read real quotes from published authors. 